\title{
A SOCIEDADE CIVIL E A ESFERA PÚBLICA EM REGIMES DEMOCRÁTICOS: NOTAS SOBRE A PARTICIPAÇÃO POPULAR*
}

Alex Pizzio**

\section{RESUMO}

Neste trabalho, são abordadas as questões relativas à relação entre a sociedade civil e a esfera pública no contexto de regimes democráticos. Nesse sentido, apresenta-se inicialmente uma breve digressão acerca do conceito de sociedade civil e a emergência de uma sociedade civil no Brasil, utilizando-se para a caracterização brasileira, dos estudos de Dagnino. Na segunda parte, será apresentada, igualmente, uma caracterização da esfera publica como espaço de discussão de demandas a serem incluídas na agenda pública. Na última parte deste trabalho, apontar-se-á para a necessidade de qualificar socialmente os atores da sociedade civil visando-se à efetividade da geração de demandas públicas como participação popular.

Palavras-chave: Sociedade civil. Esfera pública. Participação. Qualificação social.

\section{A IDÉIA DE SOCIEDADE CIVIL}

A expressão sociedade civil tem sido amplamente utilizada na atualidade. Tornou-se comum ver-se menção ao termo em jornais, programas televisivos, discursos políticos, etc. Em outros termos, presencia-se o seu emprego em uma infinidade de situações cotidianas. Isso se deve, em parte, à complexidade das sociedades contemporâneas. Entretanto, a discussão acerca da idéia de uma sociedade civil não é nova, ela remonta

\footnotetext{
* Artigo recebido em 05/03/2008 e aprovado em 25/06/2008.

** Professor de sociologia na unidade de EAD da Fundação Universidade do Tocantins. Doutorando em Ciências Sociais, graduado e mestre em ciências sociais pela Universidade do Vale do Rio dos Sinos. E-mail: alex.ps@unitins.br
} 
aos clássicos da teoria política com Hobbes, Locke e Rousseau, passando por Hegel e seus seguidores e chegando a autores contemporâneos com Habermas, Taylor e Cohen e Arato. Além disso, é possível perceber que o conceito, a despeito de sua longa trajetória histórica no campo do pensamento político, tem contado com distintos significados, dependendo das posições teóricas, do contexto histórico e da forma de autoridade política no período em questão.

Para os pensadores clássicos, a sociedade civil era definida como sinônimo de Estado, em contraposição ao estado de natureza; no entanto, mais hodiernamente, o sentido mudou. Segundo Bobbio (2003, p.34), devemos "o uso de sociedade civil no significado de esfera das relações sociais distinta da esfera das relações políticas" a autores alemães como Hegel e Marx.

Nesse sentido, Giddens (2005) tem enfatizado que, sozinhos, governo e mercado são insuficientes para solucionar os diversos desafios que têm surgido nas sociedades modernas, fazendo-se necessário fortalecer a sociedade civil (que surge como um domínio externo ao Estado e ao Mercado) e juntá-la ao governo e aos negócios. Nessa visão, grupos de voluntários, famílias, associações diversas, dentre outros,. podem desempenhar papéis vitais para lidar com questões ligadas à comunidade, que vão desde o crime à educação. E, acrescente-se, a sociedade civil desempenha papel fundamental na reivindicação de direitos e no estabelecimento de deveres, sejam eles públicos ou privados.

Esse contexto teórico tem conduzido muitos intelectuais, como Dagnino a discutirem a emergência e o papel da sociedade civil no Brasil. Para essa autora, a sociedade civil brasileira, profundamente marcada pela experiência autoritária, experimentou a partir da década de 1970, significativo ressurgimento. Ela se organizou na luta contra o autoritarismo, congregando diversos setores sociais (Igreja, Universidades, Movimentos Sociais, etc.), fato que contribuiu significativamente para uma visão homogênea da sociedade civil e deixou marcas profundas no debate teórico e político sobre o tema (DAGNINO, 2002).

A partir da volta da vigência das instituições democráticas básicas e com o implemento do processo de democratização do país, tornou-se mais clara a heterogeneidade da sociedade civil. Além disso, o retorno dos mecanismos democráticos no nível das instituições políticas acentuou o reconhecimento da importância dos mecanismos autoritários, que, enraizados historicamente, ordenaram a sociedade brasileira no 
seu conjunto, localizando a luta pela democracia no próprio terreno da sociedade civil e não apenas no Estado. Entretanto, a implementação de um processo de redemocratização não produziu o encaminhamento adequado dos problemas de exclusão e desigualdade social.

Há na sociedade brasileira, hoje, uma ênfase significativa na construção de uma nova cidadania. Uma noção de cidadania que aponta na direção de uma sociedade que se baseia no reconhecimento de seus membros como portadores de direitos. Como conseqüência imediata, tem-se observado a crescente emergência de experiências de construção de espaços públicos. Iniciado a partir de lutas contra a ditadura militar e desenvolvendo-se até os dias atuais, o processo de consolidação da democracia apresenta-se como uma demanda complexa, dinâmica e multifacetada. Ela resulta da disputa entre distintos projetos políticos que, no interior da sociedade civil e dos diversos níveis do aparato estatal, confrontam distintas concepções sobre a própria natureza e os limites desse processo.

Nessa processualidade, o efeito das políticas neoliberais veio determinar dificuldades significativas no ritmo da democratização. A mais visível é o agravamento das desigualdades sociais e econômicas. Menos notórias, são as suas conseqüências sobre a capacidade de mobilização e organização políticas da sociedade civil (DAGNINO, 2002). A autora emprega como eixo analítico a suas considerações, as relações e os encontros entre a sociedade civil e o Estado.

Dessa forma, no caso dos espaços públicos constituídos no interior da sociedade civil, o objetivo central da autora é o debate entre interesses diferenciados que possam conduzir à construção de consensos e a formulação de agendas que venham a tornar-se públicas e objeto de consideração por parte do Estado. A investigação desses espaços possibilita a análise de experiências inéditas e recentes em nosso país. Na medida em que se estabelece a convivência entre interlocutores portadores de interesses diferenciados, surgem espaços regulados democraticamente para administração de conflitos e para a construção de consensos, experiências essas que podem instaurar espaços de construção de uma dimensão propriamente pública na sociedade brasileira, distinta da regulação produzida pela lógica estrita do Estado ou do mercado. 


\section{ESFERA PÚBLICA}

Em Mudança estrutural da Esfera pública, Habermas (1984) adota como ponto de partida o desenvolvimento de estruturas mercantis na Europa, demonstrando que tal incremento levou à emergência de um espaço que ele denomina público, cuja característica principal é a possibilidade que ele abre de uma discussão livre e racional acerca do exercício da autoridade política. Em decorrência, observou-se a partir do séc. XVII o surgimento de um novo conceito de opinião pública.

Para Taylor (2000), é importante que se veja o que há de novo, pois, isso ajuda a compreender o que há de especial na esfera pública moderna. A partir daí pode-se perceber algumas diferenças básicas entre a anterior concepção de opinião pública e a visão moderna. Na primeira concepção, a opinião da humanidade é vista como: 1) irrefletida, 2) não mediada pela discussão critica, 3) passivamente inculcada em cada geração sucessiva. Já na versão moderna, em contraste, espera-se que ela: 1) seja produto de reflexão, 2) surja da discussão, 3) reflita um consenso ativamente produzido. Entretanto, a diferença deve ser vista além de uma aceitação passiva ali e do pensamento crítico aqui. A mudança crucial está no processo subjacente. Onde a opinião da humanidade era considerada como transmitida de pais e pessoas mais velhas, numa miríade de atos locais de transmissão sem vínculo entre si. A partir da nova concepção, a opinião é esboçada como tendo sido elaborada por uma discussão entre aqueles que a sustentam; discussão no âmbito da qual suas diferentes concepções foram de algum modo confrontadas e eles puderam chegar a uma idéia comum.

Taylor destaca que a liberdade na tradição ocidental baseia-se, em parte, no desenvolvimento de formas sociais em que a sociedade como um todo pode funcionar fora do âmbito do Estado. Essas formas têm sido incluídas na descrição geral de "Sociedade Civil" tomando-se o termo em seu sentido pós-hegeliano, como designação de algo distinto do Estado. Assim a sociedade civil passa a contar com uma gama de associações que não contam com o patrocínio do Estado e que, muitas vezes, dedicam-se a fins que, de modo geral, consideramos não políticos. Não se pode chamar de livre uma sociedade em que essas associações voluntárias não possam funcionar. Entretanto, existe sociedade civil num sentido forte quando, além de contar com múltiplas associações livres, a sociedade opera como um todo fora do âmbito do Estado. Taylor destaca 
que duas grandes formas de sociedade civil têm desempenhado papel de destaque na liberdade ocidental ou que assim foram consideradas. Trata-se da esfera pública e da economia de mercado.

Daí a importância da esfera pública que Taylor descreve-a como

espaço comum em que os membros da sociedade se congregam, por meio de uma variedade de meios, sejam eles impressos, eletrônicos ou em encontros diretos, para discutir questões de interesse comum para ai ser capazes de formar uma idéia comum acerca dessas questões. A esfera pública é uma característica moderna. A tal ponto que onde ela é suprimida ou manipulada, ela tem de ser simulada. (TAYLOR, 2000, p.277)

Para esse autor, a esfera pública é não só uma característica ubíqua da sociedade moderna, como também desempenha um papel crucial na autojustificação dessa sociedade como sociedade livre e autogovernada; isto é, uma sociedade em que (1) as pessoas formam livremente suas opiniões, tanto individualmente como em termos de uma idéia comum, e (2) essas idéias comuns importam: elas, de alguma maneira, agem sobre o governo ou o controlam. Justo por ter esse papel central, a esfera pública é objeto de preocupação e de crítica também nas sociedades liberais.

Assim, quando se fala de esfera pública está-se falando de uma espécie de espaço comum, em que pessoas que nunca se encontraram, entendem-se engajadas numa discussão e são capazes de chegar a uma idéia comum. A esfera pública surge como o lócus em que são elaboradas as concepções racionais que devem guiar o governo e isso passa a ser visto como característica essencial de uma sociedade livre. A esfera pública na sociedade moderna passa a diferir da república antiga pelo fato de aparecer como espaço de autodiscussão, conscientemente visto como estando fora do poder. Supõe-se que ela seja escutada pelos que ocupam o poder, mas que não é, em si, um exercício de poder. Aqui o status extrapolítico é crucial. O status extrapolítico não é definido apenas negativamente como falta de poder; pelo contrário, é visto positivamente; justamente por não ser um exercício de poder, a opinião pública pode ser idealmente desprendida do espírito partidário. Em outras palavras, vem com a esfera pública moderna a idéia de que o poder político tem de ser supervisionado e controlado por alguma coisa fora dele. O que há de novo é a natureza desse controle externo. Neste sentido, o que a esfera pública faz é permitir que a sociedade chegue a uma idéia comum, sem 
mediação da esfera política, num discurso da razão fora do poder, que não obstante é normativo para o poder.

A SOCIEDADE CIVIL COMO AGENTE DE DEMANDAS PÚBLICAS.

Segundo Avritzer (2000), os desenvolvimentos mais importantes de Habermas após a publicação da Mudança estrutural da esfera pública tiveram o papel de mostrar a presença de uma dimensão interativa nas sociedades contemporâneas. Assim, o conceito de esfera pública de Habermas amplia a participação no processo político, prevalecendo em sua teoria o fórum como um amplo lugar de discussão da sociedade civil. Desta maneira, a esfera pública aparece como caixa de ressonância das demandas provocadas pelos indivíduos na esfera privada, que são trazidas ao espaço público diretamente ou através de interlocutores.

Em Habermas, a sociedade civil tem papel fundamental na teoria democrática deliberativa. Assim, as associações e organizações livres, de caráter não estatal e não econômicas, que são vistas por ele como as estruturas de comunicação da esfera pública que formam o núcleo institucional da sociedade civil as quais são responsáveis pelo agir comunicativo. Esse agir comunicativo é formado pelas diversas associações formadas no mundo da vida, que capturam as problemáticas da esfera privada transferindo-as para a esfera pública e fazendo com que surjam temas de interesse geral, no intuito de que ocorra deliberação, além de servir como pressão para o mundo sistêmico. Desse modo, a sociedade civil passa a ser vista como composta por uma multiplicidade de atores e associações que têm voz ativa no processo argumentativo no mundo da vida. A valoração dessa visão multifacetada da sociedade descarta o mero individualismo como propulsor de motivações e decisões, a racionalidade da ação perpassa para um nível social maior de grandes e pequenos grupos que se formam no mundo da vida e dão mais consistência às decisões no nível institucional. A opinião pública formada no mundo da vida pelos diversos agentes da sociedade civil é o ponto principal na discussão do agir comunicativo na esfera pública.

Cabe aos atores da sociedade civil, nesse modelo discursivo de democracia, um papel duplo. De um lado, eles são responsáveis pela preservação e ampliação da infraestrutura comunicativa própria do mundo da vida e pela produção de microesferas públicas associadas à vida cotidiana. Ao mesmo tempo, tais atores canalizam os problemas 
tematizados na vida cotidiana para a esfera pública, tratando de apresentar novas contribuições e soluções de problemas.

Ao mesmo tempo, Habermas considera que os atores da sociedade civil não podem exercer poder administrativo, isto é, a influência destes sobre a política se faz através das mensagens que, percorrendo os mecanismos institucionalizados do Estado constitucional, alcançam os núcleos decisórios. Com isso, procura-se afastar a idéia de que a sociedade civil possa assumir funções que cabem ao Estado.

Transferindo esta discussão para o contexto brasileiro, Dagnino (2002) destaca que o cenário mais amplo dos encontros entre sociedade civil e Estado está, evidentemente, constituído pelo processo de democratização que o país atravessa desde o final dos anos oitenta. A revitalização da sociedade civil, com o aumento do associativismo, a emergência de movimentos sociais organizados, a reorganização partidária, dentre outros, fenômenos qualificados por um intenso debate sobre a natureza da democratização, constitui uma face desse processo. A outra face, resultado da primeira, é a própria democratização do Estado que, mediante o restabelecimento de vários dos procedimentos democráticos formais, abre-se ao acesso das forças políticas construídas na luta contra o regime autoritário. Assim, essas transformações no âmbito do Estado e da Sociedade Civil expressam-se em novas relações entre eles, nas quais assumem uma postura de negociação que aposta na possibilidade de uma atuação conjunta, expressa paradigmaticamente na bandeira da participação da sociedade civil.

O retrato da participação da sociedade civil brasileira nos espaços públicos, segundo a autora, demonstra que o processo de construção democrático não é linear, mas contraditório e fragmentado. Além disso, demonstra também que esse processo vincula-se a uma multiplicidade de fatores, eliminando qualquer possibilidade de conceber a sociedade civil como demiurgo do aprofundamento democrático (op.cit.).

Nesse sentido, a questão da representatividade assume facetas variadas ou é entendida de formas diversas por parte de diferentes setores da sociedade civil. Por um lado, a capacidade de pressão dos movimento sociais (MST, por exemplo) evidencia-se na realização de protestos e manifestações de massa que, assim como o número de participantes no Orçamento Participativo e sua capacidade de mobilização, atestam suas respectivas representatividades, entendidas num sentido clássico. Por outro lado, há um deslocamento no entendimento da representatividade, 
tanto por parte do Estado quanto por parte de atores da sociedade civil. No caso das ONG, por exemplo, essa representatividade parece deslocar-se para o tipo de competência que possuem: o Estado as vê como interlocutoras representativas na medida em que detém um conhecimento específico que provém do seu vínculo (passado ou presente) com determinados setores sociais: jovens, negros, mulheres, movimentos ambientais, dentre outros (DAGNINO, 2004).

A NECESSIDADE DE QUALIFICAÇÃO PARA A PLENA PARTICIPAÇÃO NA ESFERA PÚBLICA

Como visto até o momento, a sociedade civil e a esfera pública apresentam relações imbricadas. Concordando com Taylor e Habermas e atentando para o fato de que a esfera pública (que deve ser entendida no plural) passa a existir na qualidade de espaços de convivência e de debates, espaços esses que potencialmente requereriam e fortaleceriam o aprendizado e a consolidação de uma cultura de direitos por meio do exercício efetivo da cidadania.

Nesse sentido, Dagnino (2004), enfatiza as ONGs por apresentarem-se como portadoras da capacidade de representação de grupos e ou determinados setores sociais, muitas delas passam a ver-se como "representantes da sociedade civil", num entendimento particular da noção de representatividade. E mais, consideram que sua representatividade vem do fato de que expressam interesses difusos na sociedade, aos quais "dariam voz". Essa representatividade adviria, então, muito mais de uma coincidência entre esses interesses e os defendidos pelas ONG do que de uma articulação explícita, ou relação orgânica, entre estas e os portadores destes interesses.

Essa constatação é relevante, pois indica que a capacidade de participação de determinados grupos e setores sociais pode apresentar-se engessada devido à falta de aprendizado e de capacidade de apropriar-se de mecanismos de representação e participação plena na esfera pública, com conseqüências negativas para os mesmos, impedindo, assim, o exercício da cidadania plena por parte destes atores. Para melhor ilustrar este posicionamento, recorrer-se-á a um estudo realizado recentemente com catadores de recicláveis associados. Trata-se de pesquisa realizada com dois grupos de catadores associados que apresentavam um tempo de trajetória considerável, ambos existindo há mais de dez anos. Dentre 
os objetivos do estudo, buscou-se compreender e avaliar as estratégias utilizadas por esses grupos na conquista da cidadania.

No decorrer da pesquisa, observou-se que os grupos apresentaram capacidade de mobilizar-se na busca por recursos que trouxessem melhorias a suas condições de vida. Nesse processo, efetivaram algumas parcerias com empresas, organizações não governamentais e universidades. Ambos os grupos implementaram projetos sociais e obtiveram, via parcerias, fundos para implantar oficina de papel reciclado, cozinhas comunitárias, creches, melhorias na infraestrutura da comunidade, entre outras conquistas. Contudo, entre os grupos observaram-se diferenças substanciais. Constatou-se que, em um dos casos analisados, as conquistas obtidas não representaram ganho significativo em termos de autonomia do grupo, considerando-se a efetivação de demandas públicas. Estas só se concretizaram a partir da intervenção de mediadores; ou seja, pessoas ligadas às ONGs e a universidades que desenvolvem atividades de gestão ou de captação de recursos para os empreendimentos e que, no decorrer do processo, acabaram por monopolizar o saber, criando uma relação de dependência e impedindo que essa competência se traduzisse em aprendizado para o grupo. Como conseqüência geral, o grupo não apreende a andar com as próprias pernas, sendo sempre necessário o auxílio de muletas, nesse caso, os mediadores.

Não obstante no outro empreendimento, todo esse processo de busca por recursos e melhorias resultou num ganho de capacidade de mobilização e negociação que foi atingido a partir do repensar reflexivo realizado pelo grupo sobre suas práticas, ora com a comunidade, ora internamente e na interação com diversos grupos e atores sociais quando das participações no orçamento participativo. No entanto, mesmo considerando a relevância do aprendizado adquirido como práxis social, a qualificação não foi completa, deixando uma margem de dependência. Aqui, fala-se do conhecimento técnico-cognitivo como, por exemplo a elaboração de projetos para captação de recursos ou para qualificar-se a fim de participar de editais públicos. Como conseqüência, tal como acorreu com o grupo anteriormente citado, esse grupo acabou igualmente por ficar refém de entidades, instituições ou profissionais que detêm tal competência.

Desse breve relato, ficou evidente a falta e a necessidade de implementar ações que efetivamente qualifiquem socialmente. Nesse sentido, entende-se a qualificação social como 
o processo em que indivíduos alicerçados em práticas e valores experimentam um desenvolvimento em âmbito econômico, político e social, que serve de base para que os mesmos vivifiquem os laços sociais contribuindo na satisfação de objetivos comuns, no exercício da cidadania e da capacidade de se fazer representar na esfera pública, adquirindo assim, maior autonomia como sujeitos. (PIzzio, 2007, p.60)

Uma qualificação social entendida nesses termos implica perceber como suas dimensões analíticas contribuem para o desenvolvimento social. Nesse sentido, inicialmente destacam-se as práticas e os valores que implicam modos e meios, através dos quais, os sujeitos orientam e conduzem suas ações e comportamentos com vistas à realização de objetivos comuns. Outra dimensão a ser destacada diz respeito ao fortalecimento dos laços sociais, elemento fundamental na recuperação do enlaçamento social e no desenvolvimento do sentido de coletividade. Por fim, destaque-se a autonomia, que corresponde:

a capacidade e a possibilidade do indivíduo em satisfazer suas necessidades básicas, sob as condições de respeito às idéias individuais e coletivas, supondo uma relação com o mercado, onde parte das necessidades deve ser adquirida, e com o Estado, responsável por assegurar outra parte das necessidades. (Sposati, 1998, p.7)

A partir desse entendimento, verifica-se que a autonomia, além de implicar a satisfação por meio de bens materiais e simbólicos, implica a possibilidade aberta pelos sujeitos e para os sujeitos de construírem eles mesmos suas próprias histórias, ou seja, serem os autores de suas trajetórias. Dentro da perspectiva de qualificação social que esboçamos acima, a busca pela melhoria das condições de reprodução, pensadas como conquistas econômicas, passam a ser suporte de algo mais essencial, que é a participação efetiva.

Desenvolver ações visando disponibilizar os elementos e as condições necessárias para que os grupos e setores sociais que se encontram historicamente excluídos participem como cidadãos. exercendo sua cidadania sem intermediários, não é tarefa simples. Faz-se necessário um esforço conjunto entre a academia, gestores públicos e a sociedade civil, onde, dentro de uma perspectiva transdisciplinar, processos e ações sejam pensados e repensados.. 


\section{ABSTRACT}

In this paper issues concerning the relationship between civil society and the public sphere in the context of democratic regimes are discussed. Therefore, a brief tour of the concept of civil society and the emergence of a civil society in Brazil will be initially presented. Dagnino's studies will be used to characterize Brazil. In the second part, a description of the public sphere will be presented as a space for a discussion of the demands to be included in the public agenda. In the final part of this work, the need to socially qualify the actors of civil society will be pointed out, in an effort to bring about the generation of public demands as popular participation.

Keywords: Civil society. Public sphere. Participation. Social qualification.

\section{REFERÊNCIAS}

AVRITZER, L.; COSTA, S. Teoria crítica, democracia e esfera pública: concepções e usos na América Latina. Rio de Janeiro. Dados:Revista de Ciências Sócias, vol.47, no.4, p.703-728, 2004.

. Entre o dialogo e a reflexividade: a modernidade tardia e a mídia. In: ; DOMINGUES, José Mauricio. (orgs,) Teoria social e modernidade no Brasil. Belo Horizonte. Editora UFMG, 2000. p.61-83.

BOBBIO, N. Estado, governo e sociedade: para uma teoria geral da política. $10^{\circ}$ ed. São Paulo: Paz e Terra, 2003.

DAGNINO, E. Sociedade civil e espaços públicos no Brasil. São Paulo: Paz e Terra, 2002.

Sociedade Civil, participação e cidadania: do quê estamos falando? In: MATO, D. (coord.). Políticas de ciudadania y sociedad civl em tiempos de globalización, Caracas: FACES, Universidad Central de Venezuela, 2004, p.95-110.

Disponivel em: http://www.globalcult.org.ve/pub/Rocky/Libro2/Dagnino.pdf Acesso em: dezembro de 2005.

GIDDENS, A. Sociologia. $4^{\circ}$ ed. Porto Alegre: Artmed, 2005.

HABERMAS, J. Mudança estrutural da esfera pública: investigação quanto a uma categoria da sociedade burguesa. Rio de Janeiro: Ed. Tempo Brasileiro, 1984.

NÓBREGA, J. M. P. Teoria democrática contemporânea: as concepções minimalistas e seus críticos contemporâneos. Disponível em: http://www.politicahoje.com/ojs/viewarticle.php?id=86 Acesso em: 12/03/2008. 
PIZZIO, A. 2007. A economia solidária e a qualificação social dos trabalhadores empobrecidos. 2007, 154 f. Dissertação (mestrado em Ciências Sociais) - Universidade do Vale do Rio dos Sinos, São Leopoldo, RS, 2007.

SPOSATI, A. A exclusão abaixo da linha do equador. 1998. disponível em: http:// www.dpi.inpe.br/geopro/exclusao/exclu sao.pdf Acesso em: 16/10/2006.

TAYLOR, C. Argumentos filosóficos. São Paulo: Edições Loyola, 2000. 